working with older people (Hunt et al, 1997). Hamilton \& Canteen (1987) found a $16-20 \%$ rate of post-traumatic stress disorder diagnosis in veterans of the Second World War. Other studies have reported intergenerational mental health effects in veterans and groups of civilians such as Holocaust survivors. In Britain, little appropriate professional help was available after the war, which may have contributed to the psychological impact of traumatic wartime experiences. Previously recovered symptoms may reappear if the ageing process produces a sense of vulnerability (Elder \& Clipp, 1988).

Recent media coverage of changes to the criteria for entitlement to a war pension with respect to loss of hearing unfortunately coincided with the authors' separate experiences of cases of conflict with the War Pensions Agency, which is responsible for awarding and administering war pensions. In one case, the war pension of a veteran of the Second World War was reduced from 80 to $60 \%$ following a psychiatric report that was interpreted as indicating an improvement in the patient's mental state. This seriously damaged the therapeutic relationship leading to a deterioration in the patient's psychiatric disorder. We wonder whether the War Pensions Agency is aware of published research in this area and whether they take this into account when reviewing war pensions.

If, as seems possible, politically driven developments in the administration of war pensions occur, the involvement of health professionals may increase. We would therefore like to raise awareness among doctors that mental health problems in later life may be closely linked to war experiences, and that these problems may be exacerbated by the psychological issues of old age and the recent commemorations of the Second World War.

Elder, G. H. \& Clipp, E. C. (1988) Combat experience. comradeship and psychological health. In Humon Adoptotion to Severe Stress From The Holocoust to Vietnom (eds J. Wilson, $Z$. Harel \& B. Kahana). New York: Plenum.

Hamilton, J. D. \& Canteen, W. (1987) Post-traumatic stress disorder in World War II naval veterans. Hospital and Community Psychiotry, 38, 197-199.

Hunt, L., Marshall, M. \& Rowlings, C. (eds) (1997) Post Trouma in Lote Life: European Perspective on Theropeutic Work with Older People. London: Jessica Kingsley.

M. Atkins The Woodlands Centre, Hillingdon Hospital, Uxbridge, Middlesex

S. Davies Essex and Herts Community NHS Trust
Suicide and the cost-effectiveness of antidepressants

Sir: I read the correspondence by Henry (1997) and Hotopf \& Lewis (1997) with interest and wish to comment on some of the issues raised.

First, the crude cost calculations shown are not very informative since they do not include treatment costs associated with each drug class, which range from surgery attendance through to treatment for serious overdose. In the case of fatal overdose there are indirect costs associated with the suicide (e.g. support of family, loss of earnings potential). Any cost advantage of the older tricyclic antidepressants (TCAs) will soon be greatly reduced by the advent of generic selective serotonin reuptake inhibitors (SSRIs). Surely a more appropriate comparison would be of generic lofepramine with SSRIs as these compounds have broadly similar safety records in overdose.

Second, suicide is a tragic but rare event, but self-poisoning with antidepressants is more frequent and may lead to high direct treatment costs of hospital admission, cardiac monitoring and other necessary supported measures. Applying the model suggested by Henry (1997) the cost disadvantages of SSRIs and newer TCAs such as lofepramine compared with older TCAs may become less evident. For this reason, I feel a more important argument is how to make the prescribing of antidepressants more effective, in particular in terms of reduction in suicide attempt rates, regardless of the type of antidepressant used.

Third, other factors promoting fatal overdose with antidepressants may be nonspecific, such as inappropriate prescribing due to misdiagnosis, or the 'wrong' decision about treatment being made, such as suggesting that talking therapies would be more appropriate than the use of antidepressants, inadequate dosage of antidepressant being prescribed, inadequate monitoring of antidepressant prescriptions, or giving antidepressants for an inappropriately short period. Targeting these factors, which may reduce the overall effectiveness (of any antidepressant), via educational and training programmes may ultimately be more productive than 'switching' from one antidepressant class to another.

Finally, it is still not clear whether some antidepressants are more associated with increased suicide risk and suicidality in certain depressed individuals. This is an important question that has not been fully resolved.
Henry, J. A. (1997) Suicide and the cost-effectiveness of antidepressants (letter). British journal of Psychiatry. 170, 88.

Hotopt, N. Lewis, G. (1997) Suicide and the costeffectiveness of antidepressants (letter). British journal of Psychiotry, 170, 88.

S. Lynch School of Medicine, University of Leeds, Clinical Sciences Building, St James's University Hospital, Leeds LS9 7TF

\section{Crime, violence and schizophrenia}

Sir: I read with interest Dr Wessely's clear and important account of the Camberwell Study (Wessely, 1997). I disagree with only one word: his use of "reassuring" to describe some of his findings. When compared with controls his schizophrenic patients show a twofold increase in convictions for "serious assaults and violence" by male schizophrenics and a threefold increase by female schizophrenics. The controls are catchment area psychiatric patients, from an inner-city neighbourhood with high crime levels, and thus may be expected to show higher than average conviction rates. His excellent review of the literature states: “... before hospital admission we find very high rates of disturbed behaviour, very little of which will be found in hospital records". An earlier study of Maudsley patients (Noble \& Rodger, 1989) also showed high levels of violence and aggression before admission - particularly by schizophrenic patients. Dr Wessely's findings do no more than illustrate the point, well made in his review, that only a small proportion of the disturbance and violence of people with schizophrenia ever results in a criminal conviction.

The study uncovered only one killing by a schizophrenic patient, from which is calculated a homicide rate of 1 per " 7800 patient-years". Is this reassuring? Nothing can be concluded from a single incident but the rate quoted is several times the national rate $(600-700$ per year). I worked in the Camberwell catchment service for many years and know of three other homicides by catchment patients and ex-patients during the period of the study.

I share with Dr Wessely a wish to find some reassuring news about the current treatment of schizophrenia. It is important to convey information in a way which does not add to the burden of prejudice carried by our patients and their families. In its 'Manifesto for Mental Health', circulated in April 1997, The Royal College of 